\title{
Tournament-Style Debate as a Natural Resources Education Technique
}

\author{
Matthew S. Carroll,* Frederick J. Alt, Andrea M. Brandenburg, William E. Schlosser, \\ and Steven E. Daniels
}

\section{ABSTRACT}

Curricula in the natural resource professions are placing increased emphasis on course work dealing with the larger philosophical and value-related questions surrounding resource management. This development presents a challenge to instructors, particularly in terms of encouraging active student involvement in such courses. The use of tournament debate format provides one useful means for fostering such involvement while also aiding in the development of oral communication skills. The authors' experience with the use of debate suggests that certain modifications to traditional debate format aid in its successful classroom use.

A FORMIDABLE BARRIER to learning is created whenever a student views a course as merely a requirement with little intrinsic appeal or direct applicability to his or her future. Many students of the natural resource management professions often view classes in policy and other related management and social sciences as irksome. They enthusiastically take on, however, field-oriented technical courses such as dendrology, ornithology, or range plants. Classes that deal with larger philosophical questions such as, "Why manage a given parcel of land to achieve a particular end?," seem to many students as abstract and far removed from the daily activities of land management and hence of little interest. Yet a student's ability to analytically deal with these why questions is as crucial as the natural resource profession's struggle to redefine a niche in today's rapidly changing world (Gregg, 1992).

The emergence of these why questions has resulted in greater emphasis in resource management curricula on topics such as policy, ethics, and the relationship of land management to the larger society and global ecosystem (Gilbert et al., 1993). The problem remains, however, of how to teach these subjects while holding students' attention and stimulating interest. Natural resource educators often find that many natural resource students are more comfortable and active in classes that grapple with questions of how to accomplish some goal rather than those concerned with why the goal exists at all. The how questions tend to be concrete, and students easily see their application to daily decisions. The why questions are more abstract and their specific relevance is less easily grasped.

M.S. Carroll, F.J. Alt, and A.M. Brandenburg, Dep. of Natural Resource Sciences, Washington State Univ., Pullman, WA 99164-6410; W.E. Schlosser, Coop. Ext. Service, Univ. of Idaho, Clearwater County, 2200 Michigan Ave., Orofino, ID 83544-9610; and S.E. Daniels, Dep. of Forest Resources, Oregon State Univ., Corvallis, OR 97331. Received 28 Dec. 1992. *Corresponding author.

Published in J. Nat. Resour. Life Sci. Educ. 22:158-162 (1993).
The key to successful teaching is to identify how the why questions are relevant to the student. In an article on the educational process, Kraft (1978) argues that for optimum learning to take place, the students must take an active role in the process. Through this active role, students come to view new information being presented as relevant to and interrelated with information they already possess. To use his words, new knowledge should be "stirred around" with that which is already part of the individual's repertoire. Thus, Kraft argues that it is incumbent on the teacher to provide the student with an opportunity for active participation.

The purpose of this article is to describe the use of tournament debate as a way to foster active involvement of students in natural resource classes that deal with the less tangible subject areas. Specific techniques for adapting the tournament debate format to the classroom are also discussed, as are the strengths and weaknesses of debate as a teaching and learning tool.

\section{TOURNAMENT DEBATE AS A LEARNING TECHNIQUE}

Consider the example of a class in natural resource policy. In the "real world" of resource management, policy formulation is a dynamic and (we believe) interesting process for which the eventual outcome frequently has significant consequences. Policy is formulated, in part, through promotion, rhetoric, debate, and in some cases, more than a modicum of theater. Yet even the best written policy text books and readings are often found by many students to be dry and abstract. Thus, the instructor faces the problem of how to transport the dynamism of the policy process to the classroom. The adoption of a modified tournament debate format as a classroom exercise represents one effective means of accomplishing this. The tournament debate format requires that students work closely with partners in researching the debate topic in detail and then assembling the acquired information into a logically constructed debate case. The case is then argued in opposition to another team of students with the remaining class members as audience.

\section{Advantages of the Tournament Debate Format}

The use of tournament debate offers several advantages over the exclusive use of classroom discussions or the Socratic method to stimulate student involvement (Gordon, 1990). The tournament debate format requires an active orientation on the part of the students. The instructor supplies the debate proposition and an appropriate amount of background information to provide the students a start in their information assembly. The students are expected to research and think about the topic in 
depth, bringing insights gained in lecture, assigned reading, and personal experience to bear on the subject. The knowledge that they will be putting the information to work in a friendly but public competition provides students with considerable incentive for thorough preparation.

The tournament debate format also encourages students to develop advanced logical reasoning skills. Many debate cases are successfully argued, not for lack of good evidence presented by the opposition, but rather because the prevailing team directed more attention to careful logic and reasoning in argument construction. When properly guided, debate team members often engage in long fruitful discussions in arriving at a scheme concerning the construction of a debate case. If they have prepared well, they will have anticipated many of the opposition's arguments and worked out most of the logical flaws in their own case.

Formal debate can be a broadening experience, particularly when the students are asked to argue a point of view they do not personally hold. Through the process of research and debate, students should develop a more complex understanding of, and may even change their personal opinions on their issue. In one recent instance at Washington State University, a pair of students stated that they began their research in personal support of the position to which they had been assigned. They later found themselves privately agreeing with their opponents' arguments. This fact was, of course, not admitted to the class until the debate was completed.

Another advantage of tournament debate format is that it allows the class to be exposed to a reasonably indepth analysis of a number of substantive issues that may have only been briefly covered in other classroom discussion. When the formal debate is completed for a particular session, the instructor can initiate a less formal class discussion to cover any important points that the debaters have overlooked. Another advantage of the use of formal debate is that it encourages students to further develop and practice public speaking skills and the ability to "think on their feet." Resource managers in the working world are often asked to make oral presentations and to testify at hearings or in court. However, employers often bemoan the lack of communication skills on the part of natural resource management graduates. Debate offers students valuable experience and the opportunity to build confidence in expressing themselves in a professional manner.

\section{ADAPTING THE DEBATE FORMAT FOR CLASSROOM USE}

\section{The Debate Proposition}

A tournament-style debate revolves around the debate proposition (Freeley, 1981; Ericson et al., 1987). The proposition is a carefully worded, one sentence statement that typically calls for some change in the present system. For example:

1. Resolved: The Endangered Species Act should be amended to give greater consideration to the eco- nomic, cultural, and other human consequences of listing species under the provision of the Act.

2. Resolved: All cattle should be removed from public range lands.

3. Resolved: A Leopoldian land ethic should be adopted by the American forestry profession.

It is important to observe that the debate proposition should be carefully worded to avoid excessive ambiguity, but at the same time allow debaters considerable flexibility in building arguments. Note that the intent of the propositions listed above is reasonably clear, but that sufficient flexibility is built in to allow the debaters to design any of a number of specific paths to defend or oppose each proposition.

\section{Debate Organization}

A tournament-style debate consists of two opposing teams made up of two individuals each. The affirmative team argues in favor of adoption of the stated proposition. The negative team defends the status quo, and tries to refute the arguments of the affirmative team. The debate teams are formed well in advance of the actual debate, giving the team members sufficient time to gather information on the topic, form logical arguments, and define the scope and focus of their discussions. The information gathering process is critical to the success of the team. Similar to the preparation involved in developing a 20- to 25-page term paper, the research must accurately document sources, direct quotations, and the intent of supporting or damaging evidence. This information is kept on carefully filed note cards for use during the debate.

Most debate topics of interest in a natural resource management class revolve around a proposition of poli$c y$, that is, an argument about whether some action should or should not occur at some future time (this is in contrast with propositions of value or of fact that would be more likely to be of interest in a philosophy or rhetoric class). In arguing about a proposition of policy, the affirmative team must convince the audience of two critical points: the need to change the present system (accomplished by its case) and the appropriateness of the means by which it proposes to do so (for which it develops its plan).

\section{Plan and Case}

It is important to bear in mind that in tournament style debating (notably unlike U.S. presidential debates), the responsibility falls on the negative team to refute the specific case and plan that the affirmative team argues. If the negative team ignores the affirmative team's contentions and argues its own preconceived negative case, no clash will result and the debate will break down into a disorganized discussion. This arrangement may seem to place an inequitable burden on the negative team. It is important, however, that the affirmative team bears the burden of proof, since it is proposing to change the present system. To win, the negative team must raise some reasonable question in the audience's mind about the 
desirability of adopting the proposition as argued by the affirmative team.

The actual debate begins with one member of the affirmative team presenting what is called the case of the debate. This 8- (or 10)-min prepared speech ${ }^{1}$ defines the present system or point of policy relevant to the debate proposition, and why it is inadequate to deal with the current situation. This first constructive speech sets the tone for the rest of the debate and is critical to the success of the affirmative team and the clarity of the entire debate. Generally, the affirmative team will vocally present an outline of major problems with the status quo, and subpoints and ample evidence to support its position. Direct quotations from experts are generally given to substantiate arguments. Immediately following the first constructive speech by the affirmative team, the second member of the negative team is allowed to question the first affirmative speaker for 2 (or 3 ) min. This cross examination is used by the negative team to clarify points of fact, sources quoted by the affirmative speaker, and any ambiguities remaining after the presentation. This period is not to be used by the negative team as a means of presenting new information or developing arguments against information presented by the first affirmative speaker. It can be used creatively to attempt to build the credibility of the team and its case vis a vis that of its opponents.

After a brief 1-min down time, the first negative constructive speaker presents a point-by-point evaluation of the first affirmative's speech. The successful presentation by the first negative generally begins by stating what the first affirmative said, then presents evidence and argues logic that refutes each specific point made by the first affirmative speaker. The majority of the presentation is spent on a point-by-point debate defending the status quo. It is important for the first negative speaker to identify the major points made by the first affirmative speaker, and attack each significant detail during the speech. All too often, a novice debater will spend too much precious time arguing against a red herring thrown out by the first affirmative speaker, instead of devoting the majority of the speech to addressing significant points made during the preceding presentation. After completing the point-by-point attack of the affirmative team, the first negative speaker should present a summary of the speech offering both qualitative and quantitative evidence in support of the status quo.

The affirmative team is allowed a cross-examination period following the first constructive speech. This cross examination is also limited to points of clarification, explanation of logic, and sources of quotation. No new evidence is presented or argued during the cross examination by the affirmative team.

After another 1-min down-time period, the second affirmative speaker presents what is called a plan. Having pointed out the problems associated with the status quo, the affirmative team must lay out a proposal for changing the current system. This plan may include instituting new legislation or simply urging adoption of a certain

\footnotetext{
${ }^{1}$ The time allotted for speeches can vary depending on the constraints of class periods; see Table 1.
}

policy through a policy board. The plan should be comprehensive, and arguably appropriate and sufficient to solve the problems inherent in the status quo. Typically, a successful affirmative team will address specific methods by which the plan will operate, at least briefly track the legal route the plan needs to complete for adoption, and include sources of funding that would be necessary. The first portion of the presentation is also prepared in advance of the debate. However, following the presentation of the plan, the second affirmative speaker will reiterate the arguments brought up by the first negative speaker that attacked the first affirmative's presentation of the case. Again, the successful debater will give a blowby-blow description of the arguments as presented and how they respond to the comments made by the opposing team. The second affirmative presentation lasts only 8 (or 10 ) $\mathrm{min}$, so brevity is important.

Following another cross-examination period, the negative team presents its second constructive arguments. This presentation will focus on the plan presented by the second affirmative speaker. Again, the debater should present an item-by-item evaluation of the affirmative's presentation. He or she will argue specific points, attempt to discredit quoted authorities, and challenge presentations of logic by the opposing team. It is critical that the speaker challenge these points individually, and re-cap the arguments of the opposing team prior to discrediting them. If time allows, the second negative speaker will go back to the arguments presented in the case, reiterate the series of arguments presented in the first two presentations and offer new evidence, supporting view points, and attempt to discredit the logic of the opposing team.

The first half of the debate is completed when the final cross-examination by the second affirmative is finished. The debaters then have an extended down-time (we suggest $8 \mathrm{~min}$ ) to confer with one another, and refine their strategy to complete the debate. The final four presentations are 4-min rebuttals, and cannot include any new evidence, or new sources. The first speaker is from the negative team and addresses the arguments in the case. Immediately following the negative team presentation is the first affirmative speaker to rebut the arguments of the previous speaker. Next, the second negative speaker reiterates the arguments of the plan and offers new insight(s) to the arguments. The final speaker is the second affirmative and will rebut the arguments of the second negative. In addition to the duties of the final two speakers, each should end their presentation with a call to the audience to vote in favor of their respective positions.

\section{Format Modifications for Classroom Use}

One problem inherent in introducing students with no previous debate experience to the debate process is the assurance of a real point-for-point clash in both plan and case arguments. Novice team debates have a tendency to break down into disorganized discussions in which opposing teams fail to specifically address each other's arguments. One solution to this problem is to have the affirmative team submit an outline of the main contentions constituting its case and plan during the prepara- 
tory stages of the assignment. The instructor reviews the outline, suggests revisions if necessary, and passes it along to the negative team (which has presumably already conducted the bulk of its research on the topic). This allows the negative team to focus its case specifically to refute that of the affirmative. Additionally, it is helpful to repeatedly instruct both teams to be sure to specifically address each other's arguments during the course of the debate.

Another point of frequent difficulty for novice debaters is the identification and effective use of appropriate evidence for a debate. This evidence is generally collected well in advance of the contest and kept in what debaters call an evidence bank. Sources, quotes, and supporting evidence for both sides of the controversy are recorded and stored there. During the debate, the evidence will be presented citing the source, author, date, and perhaps some quotation from the authority. The citation and accurate use of sources are critical to the success of the arguments to be presented.

The second column of Table 1 describes a modified debate form for classroom use. The constructive and rebuttal speeches and cross examinations have all been reduced in presentation time. Experience suggests that a second set of rebuttal speeches may be eliminated altogether in a classroom situation because, in the hands of novice debaters, second rebuttals often tend to be redundant. Additionally, a lengthening of the standard affirmative rebuttal speech is suggested as an option, particularly if the second rebuttals are eliminated. The reason is that the first affirmative rebuttalist is required to answer the second negative constructive and the negative rebuttal arguments in one short speech, a task that even seasoned debaters consider challenging.

It is recomended that each speaker be given a minimum of 2 min after an opponent's speech to organize the response. We have also found it helpful to give the class an 8- to 10-min break between the constructive and rebuttal speeches. This allows both a change for better rebuttal preparation and fewer problems with inattention on the part of the audience. The entire debate, complete with break, preparation time, and time allowed for class discussion after the formal debate, can readily fit into a 2-h discussion section.

\section{Debate Notes}

Well-organized debate notes are a key to successful debating. It is nearly impossible to refute an opponent's arguments without a good set of notes, referred to as a flow sheet. In preparing a flow sheet, a sheet of 28 by $36 \mathrm{~cm}$ ( 11 by 14 inch) paper is used to track the arguments of the debate. The front side of the sheet is generally used for the case and the back side for the plan. The notes begin at the left-hand side of the sheet held sideways. The first negative's arguments are recorded directly across from the first affirmative's points. This pattern continues through the balance of the debate. As arguments and counter arguments are raised and recorded, they can be seen to "flow" across the columns. When an argument is inadvertently missed or purposely not contended, a
Table 1. Tournament debate format.

Standard tournament debate

format

Suggested classroom format

\begin{tabular}{|c|c|}
\hline \multicolumn{2}{|c|}{ Constructive speeches } \\
\hline $\begin{array}{l}\text { First affirmative constructive } \\
\text { (10 min) }\end{array}$ & $\begin{array}{l}\text { First affirmative constructive } \\
\text { (8 min) }\end{array}$ \\
\hline $\begin{array}{l}\text { Cross-examination by second } \\
\text { negative ( } 3 \mathrm{~min})\end{array}$ & $\begin{array}{l}\text { Cross-examination by second } \\
\text { negative }(2 \mathrm{~min})\end{array}$ \\
\hline $\begin{array}{l}\text { First negative constructive } \\
(10 \mathrm{~min})\end{array}$ & $\begin{array}{l}\text { First negative constructive } \\
(8 \mathrm{~min})\end{array}$ \\
\hline $\begin{array}{l}\text { Cross-examination by first } \\
\text { affirmative ( } 3 \mathrm{~min})\end{array}$ & $\begin{array}{l}\text { Cross-examination by first } \\
\text { affirmative }(2 \mathrm{~min})\end{array}$ \\
\hline $\begin{array}{l}\text { Second affirmative constructive } \\
\text { (10 min) }\end{array}$ & $\begin{array}{l}\text { Second affirmative constructive } \\
\text { (8 min) }\end{array}$ \\
\hline $\begin{array}{l}\text { Cross-examination by first } \\
\text { negative }(3 \mathrm{~min})\end{array}$ & $\begin{array}{l}\text { Cross-examination by first } \\
\text { negative }(2 \mathrm{~min})\end{array}$ \\
\hline $\begin{array}{l}\text { Second negative constructive } \\
\text { (10 min }\end{array}$ & $\begin{array}{l}\text { Second negative constructive } \\
(8 \mathrm{~min})\end{array}$ \\
\hline $\begin{array}{l}\text { Cross-examination by second } \\
\text { affirmative }(3 \mathrm{~min})\end{array}$ & $\begin{array}{l}\text { Cross-examination by second } \\
\text { affirmative }(2 \mathrm{~min})\end{array}$ \\
\hline \multicolumn{2}{|c|}{ Rebuttal speeches } \\
\hline $\begin{array}{l}\text { First negative rebuttal }(5 \mathrm{~min}) \\
\text { First affirmative rebuttal }(5 \mathrm{~min})\end{array}$ & $\begin{array}{l}\text { First negative rebuttal ( } 5 \mathrm{~min} \text { ) } \\
\text { First affirmative rebuttal } \\
\text { (4 to } 6 \mathrm{~min} \text { ) }\end{array}$ \\
\hline Second negative rebuttal (5 $\mathrm{min})$ & $\begin{array}{l}\text { Second negative rebuttal (optional) } \\
\text { (4 mi) }\end{array}$ \\
\hline $\begin{array}{l}\text { Second affirmative rebuttal } \\
(5 \mathrm{~min})\end{array}$ & $\begin{array}{l}\text { Second affirmative rebuttal } \\
\text { (optional) }(4 \mathrm{~min} \text { ) }\end{array}$ \\
\hline
\end{tabular}

blank spot on the flow sheet attests to this fact. The flow sheet serves as a key diagnostic tool in debate, allowing for analysis by participants and judges particularly with respect to which team "carried" which points of contention. The flow sheet is an integral component to the student's understanding of specifically addressing the issues of the debate. It can be useful to ask all class members to keep a flow sheet of each debate and to suggest that they be used as review material for exams.

\section{Demonstration}

In preparing students to debate, it can be useful to invite experienced debaters to perform a demonstration. Most universities and many high schools have debate teams that are usually eager to give a demonstration for an interested audience. It is our experience that students exposed to a demonstration by competent debaters tend to catch on much more quickly than individuals who have not oberved at least one tournament-style debate.

\section{Evaluation}

In a tournament situation, the bottom line to the team is whether a particular debate round is won or lost. In the classroom, winning and losing is of little importance except insofar as competition inspires students to put additional effort into preparation. Instead of proclaiming a winner and loser in a classroom debate round, we suggest the use of the following four criteria in evaluating a team's performance: evidence, logic, organization, and presentation. Evidence, logic, and organization can be judged in much the same way they would be evaluated in a student term paper. Presentation can be scored on the quality of the speeches themselves. Projection, tonal qualities, eye contact, clarity, timing, and conciseness should figure into the presentation score. 


\section{STRENGTHS AND WEAKNESSES OF THE DEBATE FORMAT}

A debate is certainly not the only way in which students can participate in a nonfieldwork-oriented natural resource class. Properly utilized, it is one effective way to foster an active role on the part of students. We have found that many students who initially grumble when given a debate assignment later admit that the experience was challenging and worthwhile.

One feature of tournament debate that is both a strength and a weakness, is its formality and adversarial Students will occasionally comment that the format limits discussion of creative or compromise solutions to problems that may have been excluded from the affirmative's plan. This is certainly true, but we argue that this realization is itself part of the learning process. It is important to point out that in the real world a resource manager may be asked to testify in a court or hearing room under circumstances in which he or she has no control of the format or questions asked. We contend that the debate format provides good experience in communicating in the context of a formal competitive process.

This experience also provides a basis for encouraging students to think critically about the limitations of formal processes in attempting to arrive at solutions for the "wicked" (value-related) problems of resource management (Allen and Gould, 1986). We suggest that students also be exposed to dispute resolution and mediation techniques in the course of their education (Gilbert et al., 1993). It is also very important that time be allotted after a classroom debate for a discussion fo the issues. This allows the debaters to drop their advocacy roles and reveal their privately held opinions about the issue.

\section{CONCLUSIONS}

The example that we have used in describing the application of tournament debate to natural resource education has been an undergraduate natural resources policy class. The reason is that policy classes are the settings in which we have the most experience in its use. However, the technique has potential for employment in a variety of classes ranging from 100-level introductory classes to graduate seminars (student numbers permitting). It also has the potential for use as an extracurricular activity by student clubs and student chapters of professional societies. In addition, debate could be used effectively in midcareer training, by allowing seasoned professionals to bring their years of experience to the podium.

The authors' experience suggests that tournament debate is a useful natural resource education tool. Although the format has certain limitations related to creative problem solving, it encourages students involvement in less tangible class material and fosters the development of analytic and oral communication skills. In adopting the technique, however, it is helpful to modify the format to fit the circumstances of the classroom and the experience levels of the students. The individual instructor is encouraged to develop modifications that fit the needs inherent in particular course material and classroom situations.

Thirty years ago, Zivnuska (1962), speaking about forestry, stated a compelling reason to ask natural resource professionals to learn some basic debating skills:

\begin{abstract}
One of our greatest weaknesses (as a profession) in doing battle with our critics and a clear symbol of our failure to achieve professional maturity is the lack of controversy within the profession... And until a profession develops this ability for continuous critical internal evaluation of methods and concepts, it will surely remain vulnerable to outside criticism. The truth cannot be permanently obscured simply because a profession fails to pursue it with full vigor.
\end{abstract}

The resource professions have gained a considerable measure of maturity, if for no other reason than the buffeting they have endured over the past three decades. However, as we face an increasingly uncertain environment, the ability to be logical and articulate in arguing among ourselves and with others on a professional level is more important than it has ever been. In asking students to develop logic and argumentation skills and to apply such skills to professional issues, we can help them, and ultimately the professions, cope more successfully with an increasingly complex world.

\section{ACKNOWLEDGMENT}

The senior author wishes to acknowledge that his original inspiration for and experience with the use of this technique in natural resource education was provided by Robert S. Bond, director emeritus, School of Forest Resources, Penn State University and formerly professor, Department of Forestry and Wildlife Management, University of Massachusetts.

\section{REFERENCES}

Allen, G.M., and E.M. Gould. 1986. Complexity, wickedness, and public forests. J. Forestry 84:20-23.

Ericson, J.M., J.J. Murphy, and R.B. Zeuschner. 1987. The debater's guide. Southern Illinois Univ., Press, Carbondale, IL.

Freely, A. 1981. Argumentation and debate. 5th ed. Wadsworth, Belmont, CA.

Gilbert, F.F., K.A. Blatner, M.S. Carroll, R.L. Richmond, and B.A. Zamora. 1993. Developing an integrated forest resource management curriculum: One response to the challenge. J. Forestry 91(3):17-22.

Gordon, A.M. 1990. A successful debate format for discussing resource policy issues. J. Agron. Educ. 19:103-106.

Gregg, N.T. 1992. Sustainability and politics: The cultural connection. J. Forestry 90:17-21.

Kraft, R.G. 1978. Bike riding and the art of learning. Change 10:36-42.

Zivnuska, J.A. 1962. On controversy and professional maturity. J. Forestry 60:499. 